Article

\title{
Effect of Vacuum Insulation Panels on Energy Consumption and Thermal Load Transfer between Compartments in a Three-Temperature Frost-Free Refrigerator
}

\author{
Rijing Zhao, Lin Qiao, Zijian Gao and Dong Huang *
}

School of Energy and Power Engineering, Xi'an Jiaotong University, 28 Xianning West Road, Xi'an 710049, China; zhaorijing.4@mail.xjtu.edu.cn (R.Z.); qiaolin0513@stu.xjtu.edu.cn (L.Q.); gaozijian94@stu.xjtu.edu.cn (Y.G.)

* Correspondence: d_huang@mail.xjtu.edu.cn; Tel.: +86-29-82668738; Fax: +86-29-82668725

Received: 13 February 2020; Accepted: 23 March 2020; Published: 27 March 2020

check for updates

\begin{abstract}
The three-temperature frost-free refrigerator is popular in China currently, which adopts a single evaporator and separate air ducts to distribute cold air into all compartments, i.e., the fresh food compartment (FFC), the variable temperature compartment (VTC), and the freezer compartment (FZC). Two identical refrigerators with cyclopentane insulation are comparatively studied in this article, one with vacuum insulation panels (VIPs) in two sidewalls and the other without. Results show that VIPs reduce the steady-state energy consumption of the refrigerator by $12.4 \%$ due to smaller average power input and longer compressor-off duration. The decrease in average power input originates from a shorter FFC-damper-on duration since VIPs reduce its thermal load. However, the FFC average temperature rises unexpectedly with shorter damper-on and longer damper-off durations, and induces thermal load transfer from FFC to FZC through the mixing of return air in the evaporator chamber. Consequently, FZC-only duration increases and compensates for the decrease in FFC-damper-on duration, resulting in an overall similar compressor-on duration. Simulation results of the heat transfer process through the evaporator are also provided in both cases to obtain a full view of the thermal load transfer process.
\end{abstract}

Keywords: frost-free refrigerator; vacuum insulation panel; energy consumption; thermal load transfer

\section{Introduction}

Nowadays, the three-temperature frost-free refrigerator is popular in China due to its multiple temperature zones, large volume, fast cooling, and automatic defrost. It usually includes a fresh food compartment (FFC), a variable temperature compartment (VTC), and a freezer compartment (FZC) with thermal insulation. Besides, a single evaporator is utilized with the axial/centrifugal fan and separate air ducts to distribute cooled air to all compartments for food conservation. The refrigerator has become the most energy-consuming domestic appliance, so its energy performance has been studied extensively by researchers. It is essentially an enclosed structure with cooling capacity supplied through air circulation, so the refrigeration system, insulation, auto-defrost arrangement, and air circulation/allocation are of great significance to the refrigerator performance.

Many studies were conducted on the refrigeration system and its control strategy for frost-free refrigerators. Yoon et al. [1] studied the effect of several factors on the energy performance of a dual-evaporator refrigerator, including refrigerant charge, capillary tube, and refrigerant recovery strategy. Results showed that a $7.8 \%$ energy saving was achieved by optimizing the refrigerant charge and R-capillary tube, and another $1.8 \%$ by improving charge recovery operation. Bjork and 
Palm [2,3] explored refrigerant distribution in a refrigerator under both transient and steady-state conditions, respectively. They found that losses due to charge displacement in the shut-down and start-up processes were $11 \%$ in capacity and $9 \%$ in efficiency. Visek et al. [4] studied a sequential dual-evaporator prototype by using phase change material to increase the evaporation temperature during FFC cooling. Results showed that with a condenser fan installed, the FFC-cycle energy consumption reduced by $19.9 \%$ and the overall energy consumption decreased by $5.6 \%$. Lu and Ding [5] adopted the combination control strategy for a parallel two-evaporator refrigerator based on temperature and time-sharing, and reduced compartment temperature fluctuations with much food put into FFC or FZC in a short time or with an extremely high ambient temperature. Zhang et al. [6] optimized the flow field of a spiral wire-on-tube condenser by adding structural components, so as to reduce the airflow that bypassed the condenser without actually transferring heat. The result showed that the condensation temperature dropped by $0.8^{\circ} \mathrm{C}$ and the daily energy consumption by $2.37 \%$ of the refrigerator. Zhao et al. [7] adopted the pump-down operation between FFC and FZC cycles in a parallel dual-evaporator refrigerator, and mitigated the starvation in the FFC evaporator during the initial stage of FFC cycles. Consequently, part of the capacity loss during cycle switches was recovered. Cofré-Toledo et al. [8] evaluated the integrated evaporator in a refrigerator that utilized two kinds of phase change materials. Results showed that the average temperature of the M-packs in the evaporator increased in general while that in FFC and FZC decreased. Xu and Hrnjak [9-11] studied the oil dynamics in the plenum, the discharge pipe, and the separators to obtain a deep understanding of the compressor. Besides, they developed a set of tools to study the behavior of the oil droplet in different compressor plenums. Bansal et al. [12] explored the heat transfer performance of the 'egg-crate'-type evaporator by varying several parameters. Then, they proposed a geometrically improved evaporator, which had maximum heat transfer capacity in unit weight.

Others paid attention to the effects of thermal insulation on the energy consumption of the refrigerator. Boughton et al. [13] found that the thermal load through walls and doors accounted for $60 \%$ of that in the entire refrigerator. They proposed super-insulations as the vacuum insulation panel (VIP) to be installed to reduce the thermal load. Compared with regular polyurethane or cyclopentane, VIP has a thermal conductivity $80 \%$ lower; hence, it can effectively reduce energy consumption. Thiessen and Melo [14] attached 8-mm thick VIP to the inner side of the compartment steel shell, and applied reverse heat leakage tests to study the effect of VIP coverage area and positions. They suggested that the doors and the rear wall were promising regions to install VIP to reduce energy consumption. Hammond and Evans [15] embedded VIPs into polyurethane-foamed walls of the refrigerator, and numerically calculated the potential energy savings and payback periods. The average payback was 9.7 years for refrigerators and 4.5 years for freezers. Trias et al. [16] presented an analytical Lagrange multipliers model to identify possible improvements for the refrigerator to reduce energy consumption or increase the available volume. The VIPs were necessarily embedded into sidewalls and doors to build a highly efficient direct-cooling refrigerator $(\mathrm{A}++$ and $\mathrm{A}+++)$ but with a reasonable wall thickness. Sevindir et al. [17] analytically studied the optimum location of thermal insulation panels with a given cost of the refrigerator. They suggested that if the temperature difference varies with time, the location of vacuum insulation panels should vary accordingly to obtain better heat transfer and energy consumption. Sim and Ha [18] experimentally analyzed the heat transfer characteristics through the insulating material by using the reverse heat loss method in the refrigerator freezer with VIPs for freezer sidewalls. The overall heat transfer coefficient was derived from minimizing the optimal heat loss function. Afonso and Castro [19] investigated the magnetic door seals in a domestic refrigerator quantitatively. Results showed that for the tested refrigerator, the deterioration of magnetic seals brought about 505\% more air infiltration and 341\% higher overall energy consumption. Huelsz et al. [20] developed a method to assess the thermal load through the door gasket, and found that it contributed to $5.3 \%$ of the overall thermal load of the freezer. Kim et al. [21] presented an approach to evaluate the heat transfer performance near the door gasket 
for a household refrigerator. The effect of design parameters on the heat loss through the gasket was studied, so as to reduce the energy consumption of the refrigerator.

Frosting and defrosting accounted for a large portion of energy consumption of the frost-free refrigerator. Therefore, efforts were also made to explore the frosting and defrosting process. Li et al. [22] installed an enthalpy exchanger in the FFC air duct to reduce water vapor entering the evaporator. Results showed that the enthalpy exchanger reduced frost accumulation by $18.8 \%$, and decreased the energy consumption for defrosting. However, that for cooling cycles increased owing to the decrease in the evaporation temperature and air flowrate in the air duct. Zhang et al. [23] retarded evaporator frosting by dehumidifying the inlet air of the evaporator via a desiccant-coated heat exchanger, and the desiccant was regenerated by refrigerant condensation heat. Theoretical analysis showed the COP of the refrigeration system was within 1.5-2.5 at the ambient temperature of $15-35{ }^{\circ} \mathrm{C}$, strongly dependent on the refrigerator return-air humidity and the freezer return-air temperature. Li et al. [24] added baffles in the return air duct and provided a better match between frost coverage and defrosting heat dissipation, so as to reduce the defrosting duration by making the defrosting process synchronous over the evaporator. Consequently, the defrosting efficiency was improved by $29.8 \%$. Maldonado et al. [25] compared three fan control strategies experimentally and proposed the most proper defrost starting time to achieve lower daily energy consumption. No unique fan control strategy assured the most energy-efficient operating mode, which depended strongly on frost accumulation on the evaporator. Liu et al. [26,27] proposed two new defrosting methods with outdoor air and phase-change-material thermal storage to improve the defrosting performance. Results showed that the outdoor air or phase-change-material thermal storage serving as defrosting energy could reduce the defrosting power consumption by more than $70 \%$. Melo et al. [28] evaluated the defrosting performance for three kinds of electric heaters, of which the highest defrost efficiency was $48 \%$ while the highest temperature rise was $12.4^{\circ} \mathrm{C}$. They suggested the calrod type to be the best choice when considering both its compatible defrosting performance and low cost. Zhao et al. [29-31] found that for the prevailing electric heater defrosting method in frost-free refrigerators, frost-heat mismatch and defrosting warm air intrusion are the root of high defrosting energy and FZC temperature rise in electric heater defrosting cycles. By introducing a dual-heater arrangement to better match the frost coverage and defrost heat transfer and a special fan cover to block warm air intrusion, the FZC temperature rise was reduced by $2.7^{\circ} \mathrm{C}$ and the overall energy consumption by $1.2 \%$ for the defrost cycle. Knabben et al. [32] numerically explored the defrost cycle of a 235-W heater, and found that the defrost process took $8.5 \mathrm{~min}$ with the heater uniformly covering the evaporator. By contrast, it would take only $3.5 \mathrm{~min}$ if the heater is arranged in consistence with frost coverage.

From the above articles, much work has been done on the refrigeration system, the thermal insulation, and the defrost arrangement. However, little attention has been paid to air circulation/allocation through the evaporator, which is actually a key part of the refrigerator since all compartments obtain capacity indirectly from the evaporator-cooled air. A previous work of the authors found that for the three-temperature frost-free refrigerator, the mode of air allocation to compartments significantly affected its energy consumption [33]. This study, as a supplement, explores air circulation through the evaporator and its effect on the overall performance of the refrigerator. Moreover, better thermal insulation like VIP is proved effective in enhancing refrigerator performance. However, unexpected phenomena often occur during actual use and reduce the energy-saving potential for the refrigerator, necessitating a deeper investigation.

Therefore, this article comparatively examined two refrigerators of the same three-temperature frost-free prototype, one with VIPs and the other without, to investigate the effects of VIPs on both the energy performance and air circulation dynamics of the refrigerator. The whole research was conducted experimentally and numerically. In the experiment part, two refrigerators were tested simultaneously, with both the energy consumption and operation parameter compared to obtain the effects of VIPs on the overall refrigerator performance. In the simulation part, the heat transfer processes through the evaporator were comparatively simulated for the two refrigerators, respectively, 
so as to study the effect of VIPs on air circulation dynamics. Relations between these two parts were then established, and the thermal load transfer was found from FFC to FZC. The present work will provide guidelines for the manufacturers to design and develop higher grade refrigerators.

\section{Experiment Apparatus and Procedures}

\subsection{Experiment Apparatus}

In the experiment part, two refrigerators of the identical prototype were comparatively tested, as schematically shown in Figure 1. The refrigerator prototype has one single evaporator and three distinct compartments, i.e., FFC, VTC, and FZC. During steady-cyclic operation, the cold air is supplied to all compartments with the combined control of the compressor and the air dampers. The compressor is activated once the FZC sensor temperature exceeds the preset cut-in value but shuts down when it drops below the cut-out counterpart, resulting in periodic on/off cycles. Moreover, two air dampers are installed before the air ducts to VTC and FFC, respectively, as highlighted in Figure 1. Both dampers are open initially in the on cycle but close once their respective sensor temperature reaches the cut-out values. In this way, each compartment is expected to swing in a certain range of temperatures with a target time-averaged value. Though not perfectly accurate, it is the most effective and prevailing method of temperature control in the current refrigerator market.

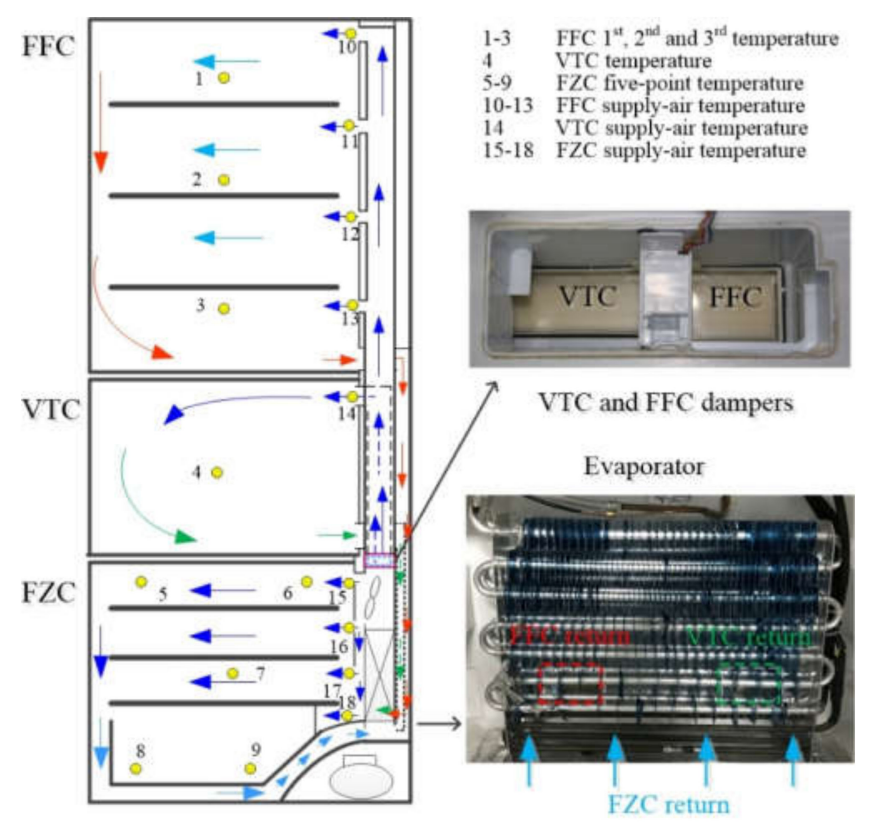

Figure 1. Schematic structure of the refrigerator with instrumentation.

The evaporator is therefore subject to three streams of return air with a distinct temperature. The FZC return air is evenly distributed along the width at the bottom of the evaporator while FFC and VTC ones are directed to only small rectangular regions in the left and right parts, respectively, as outlined in Figure 1. The air streams are mixed gradually when flowing upward through the evaporator before being blown to the three compartments separately again. The mixing and separating process of the air streams greatly affects the overall performance of the refrigerator. The detailed information of the refrigerator is listed in Table 1.

The only difference between the two refrigerators is the insulation in sidewalls. The dimensions of the refrigerators are $635 \mathrm{~mm}$ (width) $\times 1850 \mathrm{~mm}$ (height) $\times 680 \mathrm{~mm}$ (depth). One of them uses regular cyclopentane as heat insulation material for the entire refrigerator, and the cyclopentane thicknesses in the sidewalls of FFC, VTC, and FZC are 50, 80, and $80 \mathrm{~mm}$, respectively. By contrast, the other embeds VIPs in the cyclopentane-insulated sidewalls to enhance the heat insulation performance, 
with a dimension of $1500 \mathrm{~mm}$ (height) $\times 450 \mathrm{~mm}$ (depth) $\times 15 \mathrm{~mm}$ (depth). The layout of VIPs is illustrated in Figure 2. In the height direction, the spacing between the refrigerator top and the VIP top is $100 \mathrm{~mm}$ while that from the refrigerator bottom to the VIP bottom is $250 \mathrm{~mm}$. In the depth direction, VIP is in the middle of each sidewall of the refrigerator. For comparison, the thermal conductivity was $0.022 \mathrm{~W} \cdot \mathrm{m}^{-1} \cdot \mathrm{K}^{-1}$ for cyclopentane but $0.0039 \mathrm{~W} \cdot \mathrm{m}^{-1} \cdot \mathrm{K}^{-1}$ for VIP. To be cited briefly, the regular and enhanced insulation refrigerators are denoted as the baseline case and VIP case, respectively, in this article.

Table 1. Technical specification of the refrigerator.

\begin{tabular}{cccc}
\hline Items & Parameters & Items & Parameters \\
\hline Refrigerator model & BCD-345W & Compressor & Jiaxipera VTH1113Y \\
\hline FZC volume/L & 117 & FFC volume/L & 193 \\
\hline VTC volume/L & 35 & Weight $/ \mathrm{kg}$ & 95 \\
\hline Throttle device & Capillary tube & Blowing agent & Cyclopentane/VIP \\
\hline Climate class & ST & Refrigerant & R600a \\
\hline Defrost system & Auto electric defrost & Refrigerant charge/g & 52 \\
\hline
\end{tabular}

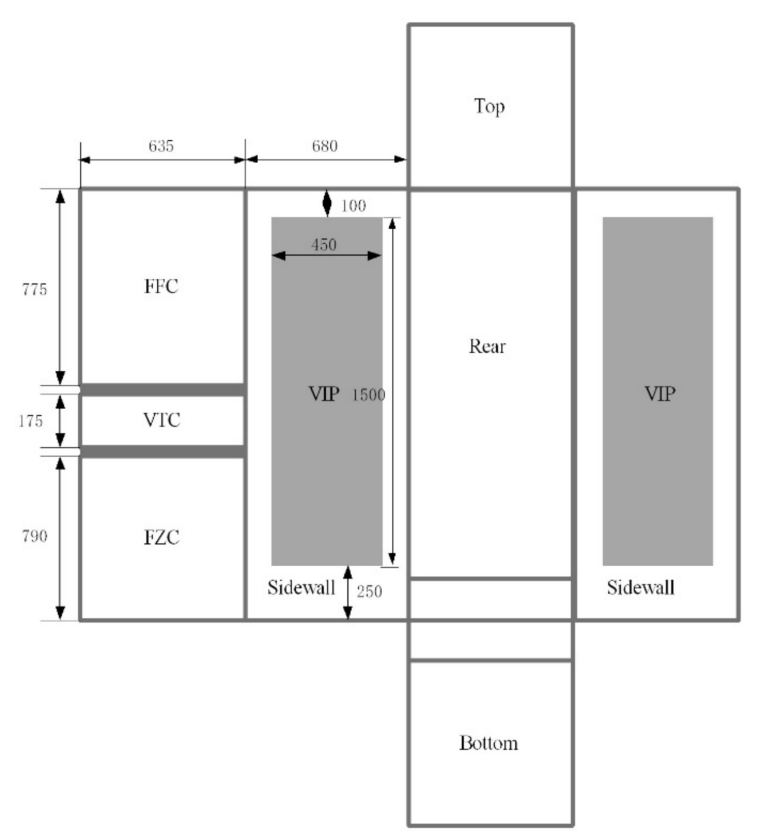

Figure 2. Layout of VIPs embedded into two sidewalls of the refrigerator. (VIP means vacuum insulation panel as defined in the text)

\subsection{Test Procedures}

The refrigerators were tested simultaneously in a psychrometric chamber, where the temperature was set at $32.0 \pm 0.5^{\circ} \mathrm{C}$ and a relative humidity of about $50 \%$. A set of data acquisition systems was utilized to collect experiment outputs from the instrumentations in the refrigerator. T-type thermocouples were pasted on the evaporator and placed inside the compartments following Chinese Standard GB 12021.2-2015, as shown in Figure 1. The thermocouples were pre-calibrated in the range of $-30 \sim 200{ }^{\circ} \mathrm{C}$, and the error was $\pm 0.2{ }^{\circ} \mathrm{C}$. Humidity sensors were located at the return air outlets in FFC, VTC, and FZC, respectively, to detect the humidity of each return air stream to the evaporator. Besides, a power meter with $\pm 0.4 \mathrm{~W}$ error was accessed to monitor the power input of the refrigerator, so as to further obtain its energy consumption. The single-sample method [34] was adopted to estimate the uncertainties in this study. 
During tests, the time-averaged temperatures for FFC, VTC, and FZC were set $4 \pm 2,-6 \pm 2$, and $-18 \pm 2{ }^{\circ} \mathrm{C}$ in empty conditions, respectively. Both refrigerators were tested until four defrost cycles were completed. Before the first defrost cycle was the initial pull-down process, which used special control strategies to cool down all compartments from theambient temperature to their respective target values quickly and synchronously. Before the last three, however, consistent control logic was adopted during steady-cyclic operations. Therefore, temperature curves for both refrigerators showed good repetitiveness, as shown in Figure 3. The cooling cycles between the third and the fourth defrost actions were finally chosen to be studied. In this way, the disturbance of the initial warmer ambient air would be eliminated to the utmost extent. There were 28 steady on/off cycles between the third and the fourth defrost actions in the baseline case and 27 in the VIP case of the refrigerator. The average parameters for all the steady cycles were used to calculate the overall performance, while the specific value for the 14th one was picked out to study the dynamics of the tested refrigerator. The test scenarios are presented in Table 2.

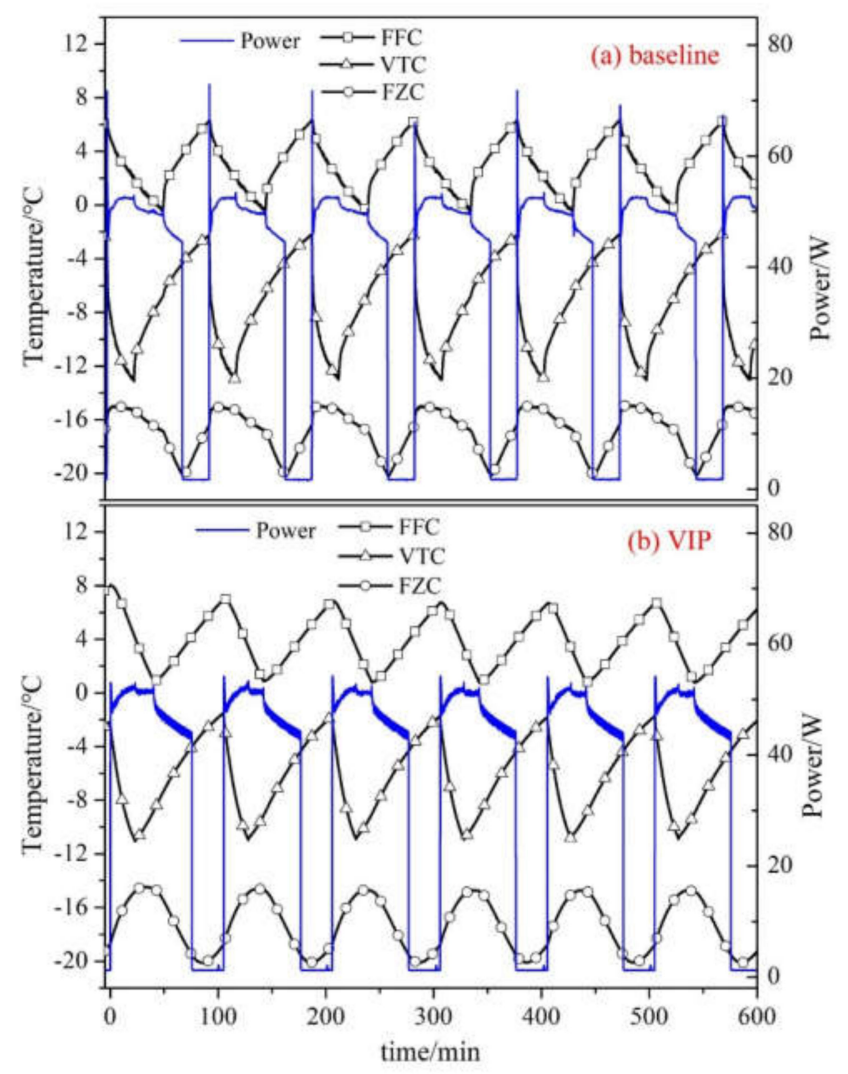

Figure 3. Steady cyclic operations of the refrigerator: (a) baseline case; (b) VIP case. (VIP means vacuum insulation panel as defined in the text).

Figure 3 also shows that under GB 12021.2-2015 conditions, the air damper for VTC always closed earlier than for FFC during the on cycle of the refrigerator, since the volume of VTC (35 L) was much smaller than that of FFC (193 L). Therefore, there are actually three different modes of air dampers during the on cycles of the refrigerators. Initially, both air dampers were open, and the cold air from the evaporator was supplied to all compartments. Then, the damper for VTC closed after it reached the cut-out temperature, allowing cold air to be blown to FFC and FZC thereafter. Finally, that for FFC closed too once it reached the cut-out temperature, and the cold air was supplied only to FZC until it achieved the cut-out temperature. For a brief citation in this article, the above three modes of operation during on cycles of the refrigerator are denoted as 'VTC+FFC+FZC', 'FFC+FZC', and 'FZC-only', respectively. 
Table 2. Test scenarios of this research.

\begin{tabular}{|c|c|c|}
\hline Cases & Baseline & VIP \\
\hline Prototype & \multicolumn{2}{|c|}{$\begin{array}{l}\text { three-temperature, single evaporator, capacity supplied by axial fan and } \\
\text { air ducts }\end{array}$} \\
\hline Insulation & Only cyclopentane & VIPs embedded in cyclopentane \\
\hline Instruments & \multicolumn{2}{|c|}{$\begin{array}{c}\text { Thermocouples in cabinets, on evaporator surface and in air ducts; } \\
\text { Humidity sensors in return air inlets in all cabinets; } \\
\text { Power meter before the plug of the refrigerator. }\end{array}$} \\
\hline Test cycles & \multicolumn{2}{|c|}{$\begin{array}{l}\text { Four cooling/defrosting cycles with 1st pulling-downing and 2nd } \sim 4 \text { th } \\
\text { normal cooling; }\end{array}$} \\
\hline Simulation & \multicolumn{2}{|c|}{$\begin{array}{l}\text { Heat transfer on evaporator surface based on temperature/humidity of } \\
\text { return air detected by thermocouples and humidity sensors. }\end{array}$} \\
\hline
\end{tabular}

\section{Results and Discussion}

\subsection{Overall Energy Performance}

The average outputs for all steady on/off cycles were compared first to study the effects of VIP on energy performance of the refrigerator. Table 3 lists the performance parameters of the refrigerators in both cases. In all, the steady-state energy consumption is reduced by $12.4 \%$ in the VIP case than in the baseline case. Besides, the average power input during on cycles drops from 37.29 to $34.30 \mathrm{~W}$ and the compressor-on ratio from $73.68 \%$ to $70.75 \%$ with VIPs, which altogether lead to a reduction in the energy consumption of the refrigerator.

Table 3. Comparison of refrigerator performance between baseline and VIP cases.

\begin{tabular}{cccc}
\hline Item & Baseline & VIP & Deviation \\
\hline VTC+FFC+FZC duration/min & 24.67 & 22.07 & -2.6 \\
\hline FF+FZC duration/min & 27.5 & 14.6 & -12.9 \\
\hline FZC-only duration/min & 17.83 & 34.13 & +16.3 \\
\hline Compressor-on duration/min & 70.0 & 70.8 & +0.8 \\
\hline Compressor-off duration/min & 25.0 & 29.27 & +4.27 \\
\hline Compressor-on ratio/\% & 73.68 & 70.75 & -2.93 \\
\hline Average power/W & 37.29 & 34.30 & $-8.0 \%$ \\
\hline Steady-state energy consumption/kW•24 h & 0.659 & 0.577 & $-12.4 \%$ \\
\hline
\end{tabular}

The lower compressor-on ratio results from the longer compressor-off duration in the VIP case. Table 3 shows that the compressor-off duration is 4.27 min longer in the VIP case than in the baseline case, indicating smaller heat leakage from high-temperature ambience with better thermal insulation of VIPs. Surprisingly, the compressor-on duration hardly differs. Table 3 shows that the VTC+FFC+FZC and FFC+FZC durations altogether are $15.5 \mathrm{~min}$ shorter in the VIP case than in the baseline case, but the FZC-only duration is 16.3 min longer. Therefore, the overall compressor-on duration is similar in both cases.

The larger portion of the FZC-only mode in the on cycle further reduces the average power input in the VIP case. Figure 3 shows that the power input is generally larger in the VTC+FFC+FZC and FFC+FZC modes than in the FZC-only mode. The reason is that while VTC and FFC dampers are open, the return air to the evaporator is warmer due to the higher cabinet temperatures in these two compartments. The warmer return air raises the evaporation temperature and then the compressor suction pressure, which contributes to the larger power input. In other words, the longer FZC-only mode helps to reduce the time-averaged power input in the VIP case. 


\subsection{Dynamic Characteristics}

Then, the 14th on/off cycles were picked out to study the effects of VIP on the dynamic characteristics of the refrigerator. Figure 4 illustrates all cabinet temperatures during the 14th on/off cycle in both cases. The VTC+FFC+FZC, FFC+FZC, and FZC-only modes last for 25, 26.8, and $18.3 \mathrm{~min}$ in the baseline case but 21.9, 14.3, and $34.1 \mathrm{~min}$ in the VIP case, respectively. Again, the former two modes (also the entire FFC damper-on duration) shortens by $15.5 \mathrm{~min}$ while the FZC-only mode increases by $15.8 \mathrm{~min}$ with VIPs embedded. Therefore, the compressor-on duration is almost equal in both cases. Besides, the time-averaged temperatures for FFC, VTC, and FZC vary from $3.2,-6.3$, and $-16.8^{\circ} \mathrm{C}$ in the baseline case to $4.4-6.1$, and $-17.9^{\circ} \mathrm{C}$ in the VIP case, respectively, as shown in Table 4. Obviously, the FFC temperature increases while FZC temperature descends with VIPs embedded. By contrast, the VTC temperature hardly changes.

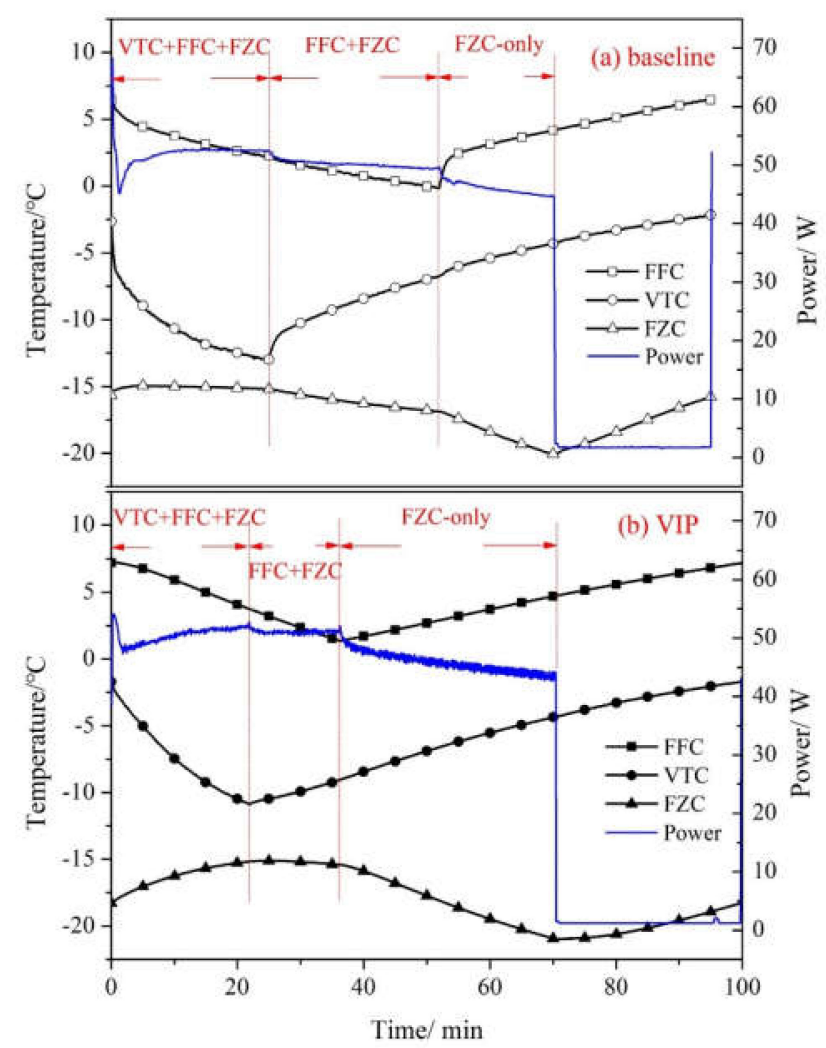

Figure 4. Variations in cabinet temperature during the 14th on/off cycle: (a) baseline case; (b) VIP case.

Table 4. Time-averaged cabinet temperature during the 14th on/off cycle in both cases.

\begin{tabular}{ccc}
\hline Cabinet & Baseline & VIP \\
\hline $\mathrm{FFC} /{ }^{\circ} \mathrm{C}$ & 3.2 & 4.4 \\
\hline $\mathrm{VTC} /{ }^{\circ} \mathrm{C}$ & -6.3 & -6.1 \\
\hline $\mathrm{FZC} /{ }^{\circ} \mathrm{C}$ & -16.8 & -17.9 \\
\hline
\end{tabular}

Figure 4 shows a faster drop rate in the FFC temperature in the VIP case than in the baseline case. The FFC average temperature drops from $6.4{ }^{\circ} \mathrm{C}$ at $0 \mathrm{~min}$ to $-0.2^{\circ} \mathrm{C}$ at $51.83 \mathrm{~min}$ in the baseline case, with an average rate of $1.28{ }^{\circ} \mathrm{C}$ per $10 \mathrm{~min}$. By contrast, it drops from $7.2^{\circ} \mathrm{C}$ at 0 min to $1.4{ }^{\circ} \mathrm{C}$ at $36.27 \mathrm{~min}$ in the VIP case, with an average rate of $1.61^{\circ} \mathrm{C}$ per $10 \mathrm{~min}$. Obviously, VIPs reduce the thermal load for FFC and then raise its cooling rate by $27.8 \%$, which leads to its shorter damper-on duration. The shorter damper-on duration and the longer damper-off period further lead to an increase in the time-averaged temperature of FFC, from $3.2^{\circ} \mathrm{C}$ in the baseline case to $4.4^{\circ} \mathrm{C}$ in the VIP case. 
VIPs also reduce the FZC thermal load and should theoretically raise its cooling rate. However, it hardly happens in this study. Figure 4 shows that FZC average temperature drops from $-15.6{ }^{\circ} \mathrm{C}$ at $0 \mathrm{~min}$ to $-20.1^{\circ} \mathrm{C}$ at $70.33 \mathrm{~min}$ in the baseline case, with an average rate of $0.64^{\circ} \mathrm{C}$ per $10 \mathrm{~min}$. By contrast, it descends from $-18.2{ }^{\circ} \mathrm{C}$ at $0 \mathrm{~min}$ to $-20.9^{\circ} \mathrm{C}$ at $70.47 \mathrm{~min}$ in the VIP case, with an average rate of $0.27^{\circ} \mathrm{C}$ per $10 \mathrm{~min}$. That is to say, the FZC cooling rate hardly increases but decreases on average with VIPs embedded. Figure 4 shows that the FZC average temperature drops almost all the way in the baseline case. By contrast, it increases initially for a long time in the VIP case, which results in a longer FZC-only mode and then an overall similar compressor-on duration in this case. The longer FZC-only mode dominated a decrease in the time-averaged FZC temperature, from $-16.8^{\circ} \mathrm{C}$ in the baseline case to $-17.9^{\circ} \mathrm{C}$ in the VIP case.

The initial rise in FZC temperature is a result of the higher supply-air temperature in the VIP case. Figure 5 comparatively presents the temperatures of the FZC supply air, FZC cabinet air, and the evaporator inlet in both cases. In the baseline case, the supply air temperature is always lower than the cabinet air for FZC. In the VIP case, however, the supply air is warmer than the cabinet air in the initial stage of the on cycle, which leads to the initial rise in the FZC cabinet air temperature. FZC supply air is actually a portion of evaporator outlet air, which originates from the mixture of three streams of return air from VTC, FFC, and FZC after being cooled through the evaporator. In the VIP case, the evaporator outlet air is warmer than the FZC cabinet air, indicating that some thermal load is transferred from FFC to FZC in the initial stage of the on cycle.

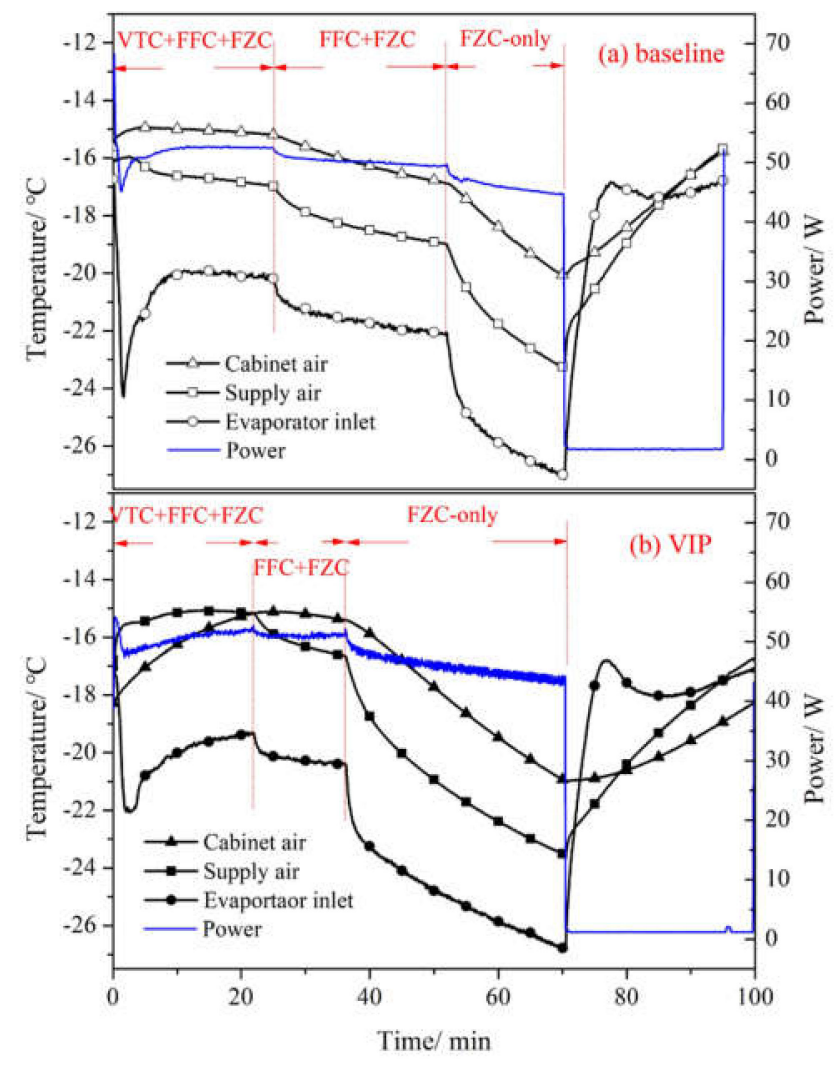

Figure 5. FZC cabinet air, FZC supply air, and evaporator temperatures during the 14th on/off cycle: (a) baseline case; (b) VIP case. (FZC means freezer compartment as defined in the text).

\subsection{Thermal Load Transfer}

The experiment tests show that VIPs reduce the daily energy consumption for the refrigerator by $12.4 \%$ due to better insulation. However, thermal load transfer from FFC to FZC happens. VIPs reduce the FFC thermal load and therefore shorten its cooling period, which unexpectedly raises its time-averaged cabinet temperature. Then, warmer return air from FFC further increases the 
evaporator outlet air temperature after mixing with FZC and VTC return air in the evaporator chamber. Consequently, FZC supply air is warmer than its cabinet air during the FFC-damper-on period, resulting in the initial increase in the FZC temperature during the on cycle. In this section, a simulation was conducted to depict the air temperature distribution in the evaporator chamber, so as to obtain more details of the thermal load transfer through the evaporator. Note that this simulation is part of the heat and mass (frost) transfer of the evaporator subjected to three streams of return air with distinct temperature/humidity. Only the heat transfer part is presented here.

A simulation was conducted using the element by element method. The evaporator was a fin-tube type, as schematically shown in Figure 6a, and its parameters are listed in Table 5 . In the simulation study, the bends of the evaporator were neglected, and the tubes were divided into elements based on fins. The inner element is sandwiched by the adjacent fins, while the lateral element is a half of the inner one, as schematically shown in Figure 6b. Each element was calculated individually first, and then coupled according to the equal-pressure rules. The input parameters of the upward elements are the output parameters of the downward ones.

(a)

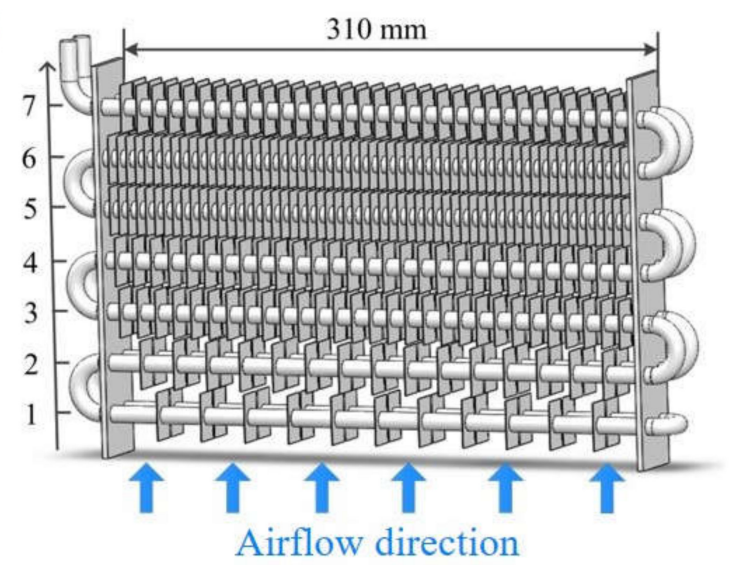

(b)

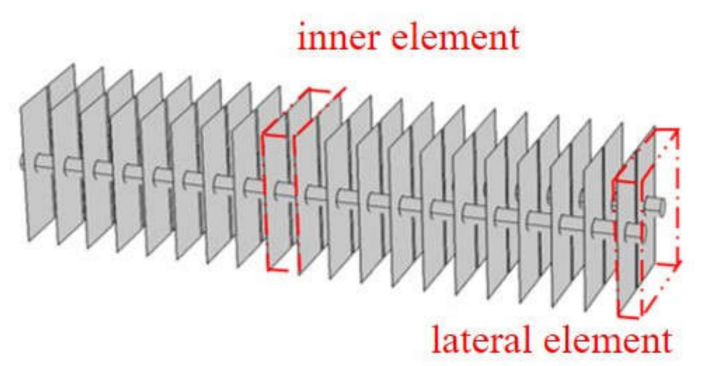

Figure 6. Schematic diagrams of the evaporator and the elements: (a) evaporator; (b) elements.

Table 5. Parameters for the evaporator of the refrigerator.

\begin{tabular}{cccc}
\hline Items & Parameters & Items & Parameters \\
\hline Rows & 2 & Tubes per row & 7 \\
\hline Fin thickness & $0.15 \mathrm{~mm}$ & Fin height & $28 \mathrm{~mm}$ \\
\hline Fin width & $60 \mathrm{~mm}$ & Tube length & $310 \mathrm{~mm}$ \\
\hline Tube out diameter & $8 \mathrm{~mm}$ & Tube pitch & $30 \mathrm{~mm}$ \\
\hline Row pitch & $30 \mathrm{~mm}$ & Fin type & Flat \\
\hline Fins in each row & $11,15,29,29,58,58,33$ (from tube 1 to 7 in Figure 6)
\end{tabular}


To improve the convergence of the simulation, several assumptions were made for the model. First, the temperature of the tubes and fins are identical throughout the evaporator. Second, frost is uniformly distributed in each element and the heat transfer process inside frost is one-dimensional and quasi-static. Third, two streams of return air in each half of the evaporator are already mixed thoroughly before entering the evaporator, and the proportion of each is $50 \%$ under the fan curve according to the manufacturer.

Simulation was conducted at $20 \mathrm{~min}$ of the on cycle for both cases to explain the difference in FZC temperature variation. Temperatures of the return air at $20 \mathrm{~min}$ are listed in Table 6 , and the real-time evaporator surface temperatures in both cases are also included. The air-side convective heat transfer coefficient was calculated with the Karatas' correlation [35], and the air-side pressure drop was obtained using the correlation of Kays and London [36]. Besides, the characteristics curve of the axial fan shown in Figure 7 was obtained from the manufacturer to calculate the real-time air flow rate through the evaporator.

Table 6. Temperature of the return air and evaporator surface at $20 \mathrm{~min}$ in both cases.

\begin{tabular}{ccccc}
\hline Cases & FZC Return Air & FFC Return Air & VTC Return Air & Evaporator Surface \\
\hline baseline $/{ }^{\circ} \mathrm{C}$ & -13.5 & 0.7 & -10.2 & -21.9 \\
\hline $\mathrm{VIP} /{ }^{\circ} \mathrm{C}$ & -12.8 & 2.6 & -10.7 & -20.1 \\
\hline
\end{tabular}

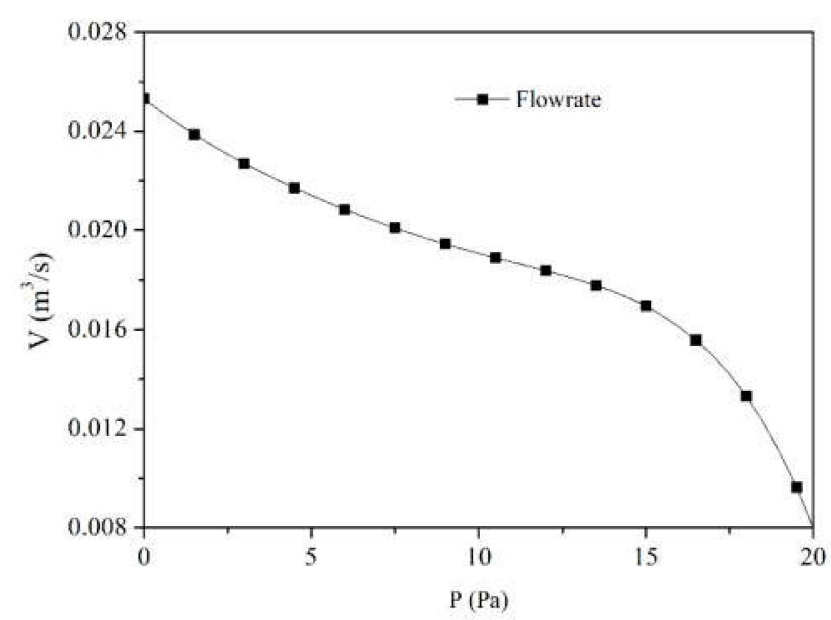

Figure 7. Characteristic curve for the axial fan of the evaporator.

Figure 8 shows the temperature distribution inside the evaporator area at $20 \mathrm{~min}$ for both cases, and Table 7 lists the comparison between the average temperatures of the evaporator outlet air in thr simulation and experiment results. Seen from Table 7, the deviations between the simulation and experiment results are less than $0.2^{\circ} \mathrm{C}$ in both cases, validating the accuracy of the simulation.

In both cases, the air temperature is distinct between the two halves at the bottom of the evaporator, as shown in Figure 8. The left half is much warmer than the right half due to the higher temperature of the FFC return air than the VTC one. Then, during the upward flowing and cooling, air in the two halves get mixed gradually in the horizontal direction and the temperature difference between the two halves become smaller at the top. The air mixing is mainly a result of redistribution under the non-uniform frosting on the evaporator, because the left part is more susceptible to frost with higher-humidity return air. Besides, the non-uniform fin arrangement also promotes air redistribution when it is flowing upward. 


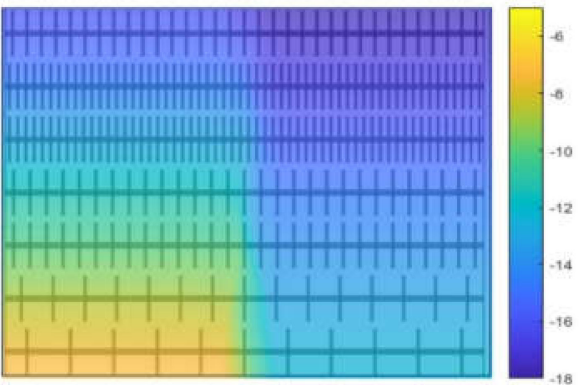

(a) baseline

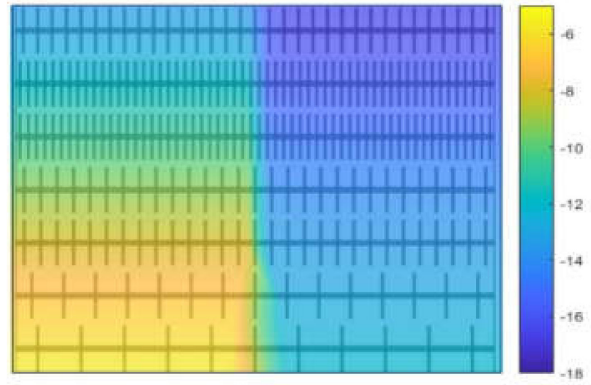

(b) VIP

Figure 8. Simulated air temperature distribution at $20 \mathrm{~min}$ of the evaporator area in both cases: (a) baseline case; (b) VIP case. (VIP means vacuum insulation panel as defined in the text).

Table 7. Average temperature of evaporator outlet air at $20 \mathrm{~min}$ in the simulation and experiment.

\begin{tabular}{ccc}
\hline Case & Baseline & VIP \\
\hline Experiment $/{ }^{\circ} \mathrm{C}$ & -17.4 & -15.3 \\
\hline Simulation $/{ }^{\circ} \mathrm{C}$ & -17.2 & -15.2 \\
\hline
\end{tabular}

VIPs bring about thermal load transfer from FFC to FZC. Figure 8 shows that the evaporator outlet air is generally warmer in the VIP case than in the baseline case, which originates from the higher FFC return air temperature in the VIP case. The warmer FFC return air first raises the temperature of the left half of the evaporator after mixing with the FZC return air. Figure 8 shows that the temperature in the left half of the evaporator is obviously higher in the VIP case than in the baseline case. Then, with the mixing and redistribution in the horizontal direction, the warm air in the left part gradually raises the temperature of the whole evaporator. Consequently, the evaporator outlet temperature in both halves of the evaporator is higher in the VIP case than in the baseline case. Unfortunately, the average temperature of the evaporator outlet air is even higher than that of the FZC cabinet air, leading to the initial increase in the FZC cabinet air temperature in the VIP case.

\section{Conclusions}

(1) VIPs reduce the steady-state energy consumption of the refrigerator by $12.4 \%$, ascribed to the $8.0 \%$ lower average power input and $2.9 \%$ smaller compressor-off duration.

(2) VIPs accelerate FFC cooling by $27.8 \%$ due to better thermal insulation, and therefore shorten the FFC-damper-on duration by $15.5 \mathrm{~min}$. However, the shorter damper-on and longer damper-off durations raise the FFC average temperature by $1.2^{\circ} \mathrm{C}$.

(3) The higher FFC cabinet temperature in the VIP case induces thermal load transfer from FFC to FZC through the mixing of return air in the evaporator chamber, thus increasing the FZC-only duration by $15.8 \mathrm{~min}$. Consequently, the compressor-on duration is hardly reduced.

(4) The simulation results of the heat transfer process through the evaporator in both the baseline and VIP cases were provided to obtain a full view of the thermal load transfer process.

Author Contributions: D.H. provided guidance and supervision; R.Z. implemented the main research, analyzed the results and wrote the article; L.Q. made contribution to the simulation work; Z.G. provided help for formal analysis. All authors have read and agreed to the published version of the manuscript.

Funding: The present work is supported by the National Natural Science Foundation of China (No. 51806161) and China Postdoctoral Science Foundation (NO. 2019M653613).

Conflicts of Interest: The authors declare no conflict of interest. 


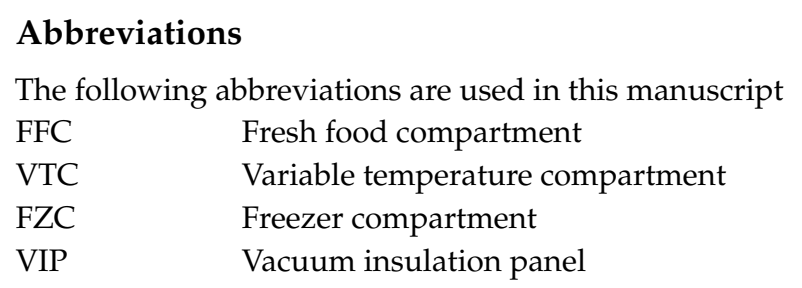

\section{References}

1. Yoon, W.J.; Jung, H.W.; Chung, H.J.; Kim, Y. Performance optimization of a two-circuit cycle with parallel evaporators for a domestic refrigerator-freezer. Int. J. Refrig. 2011, 34, 216-224. [CrossRef]

2. Björk, E.; Palm, B. Refrigerant mass charge distribution in a domestic refrigerator. Part I: Transient conditions. Appl. Therm. Eng. 2006, 26, 829-837. [CrossRef]

3. Björk, E.; Palm, B. Refrigerant mass charge distribution in a domestic refrigerator. Part II: Steady state condition. Appl. Therm. Eng. 2006, 26, 866-871. [CrossRef]

4. Visek, M.; Jappolo, C.M.; Molinaroli, L.; Olivani, A. Advanced sequential dual-evaporator domestic refrigerator/freezer: System energy optimization. Int. J. Refrig. 2014, 43, 71-79. [CrossRef]

5. Lu, Z.; Ding, G. Temperature and time-sharing running combination control strategy of two-circuit cycle refrigerator-freezer with parallel evaporators. Appl. Therm. Eng. 2006, 26, 1208-1217. [CrossRef]

6. Zhang, Z.; Huang, D.; Zhao, R.; Leng, Y. Effect of airflow field optimization around spiral wire-on-tube condenser on a frost-free refrigerator performance. Appl. Therm. Eng. 2017, 114, 785-792. [CrossRef]

7. Zhao, R.; Huang, D.; Peng, X.; Zhang, Y. Switch loss of a frost-free refrigerator-freezer with parallel dual-evaporator refrigeration system and its mitigation. Sci. Tech. Built Env. 2019, 25, 387-395. [CrossRef]

8. Cofré-Toledo, J.; Vasco, D.A.; Isaza-Roldán, C.A.; Tangarife, J.A. Evaluation of an integrated household refrigerator evaporator with two eutectic phase-change materials. Int. J. Refrig. 2018, 93, 29-37. [CrossRef]

9. $\mathrm{Xu}$, J.; Hrnjak, P. Formation, distribution, and movement of oil droplets in the compressor plenum. Int. J. Refrig. 2018, 93, 184-194. [CrossRef]

10. Xu, J.; Hrnjak, P. Coalescing oil separator for compressors. Int. J. Refrig. 2019, 106, 41-53. [CrossRef]

11. Xu, J.; Hrnjak, P. Characteristics of oil annular-mist flow in the compressor discharge pipe. Int. J. Refrig. 2019, 107, 145-154. [CrossRef]

12. Bansal, P.K.; Wich, T.; Browne, M.W. Optimisation of egg-crate type evaporators in domestic refrigerators. Appl. Therm. Eng. 2001, 21, 751-770. [CrossRef]

13. Boughton, B.E.; Clausing, A.M.; Newell, T.A. An investigation of household refrigerator cabinet thermal loads. HVACER Research 1996, 2, 135-147.

14. Thiessen, S.; Knabben, F.T.; Melo, C.; Gonçalves, J.M. A study on the effectiveness of applying vacuum insulation panelss in domestic refrigerators. Int. J. Refrig. 2018, 96, 10-16. [CrossRef]

15. Hammond, E.C.; Evans, J.A. Application of vacuum insulation panelss in cold chain-analysis of viability. Int. J. Refrig. 2014, 47, 58-65. [CrossRef]

16. Trias, F.X.; Oliet, C.; Rigola, J.; Pérez-Segarra, C.D. A simple optimization approach for the insulation thickness distribution in household refrigerators. Int. J. Refrig. 2018, 93, 169-175. [CrossRef]

17. Sevindir, M.K.; Demir, H.; Ağra Atayılmaz, S.Ö.; Teke, İ. Modelling the optimum distribution of insulation material. Renew. Energy 2017, 113, 74-84. [CrossRef]

18. Sim, J.S.; Ha, J.S. Experimental study of heat transfer characteristics for a refrigerator by using reverse heat loss method. Int. Commun. Heat Mass Transf. 2011, 38, 572-576. [CrossRef]

19. Afonso, C.; Castro, M. Air infiltration in domestic refrigerators: The influence of the magnetic seals conservation. Int. J. Refrig. 2010, 33, 856-867. [CrossRef]

20. Huelsz, G.; Gómez, F.; Piñeirua, M.; Rojas, J.; Alba, M.; Guerra, V. Evaluation of refrigerator/freezer gasket thermal loads. HVAC R Res. 2011, 17, 133-143. [CrossRef]

21. Kim, H.S.; Sim, J.S.; Ha, J.S. A study on the heat transfer characteristics near the magnetic door gasket of a refrigerator. Heat Mass Transf. 2011, 38, 1226-1231. [CrossRef]

22. Li, Z.Q.; Zhao, D.; Ding, G.L.; Ren, T.; Miao, S.; Han, X. Effect of enthalpy exchanger on reducing frost accumulation on evaporator in frost-free refrigerator. Int. J. Refrig. 2018, 89, 51-60. [CrossRef] 
23. Zhang, L.; Fujinawa, T.; Saikawa, M. Theoretical study of a frost-free household refrigerator-freezer. Int. J. Refrig. 2016, 62, 60-71. [CrossRef]

24. Li, Z.Q.; Zhao, D.; Ding, G.L.; Ren, T.; Miao, S.; Han, X.; Noda, T. Improving defrosting performance by controlling frost distribution to match defrosting heat distribution in frost-free household refrigerators. Int. J. Refrig. 2017, 77, 136-148. [CrossRef]

25. Maldonado, J.M.; Zsembinszki, G.; Gracia, A.D.; Moreno, P.; Albets, X.; González, M.A.; Gabeze, L.F. Control strategies for defrost and evaporator fans operation in walk-in freezers. Int. J. Refrig. 2018, 91, 101-110. [CrossRef]

26. Liu, Z.B.; Gao, W.Q.; Lang, H.W.; Chi, Y.Y. Experimental study on new type of defrosting system using outdoor air for frost-free household refrigerators. Appl. Therm. Eng. 2018, 134, 256-265. [CrossRef]

27. Liu, Z.B.; Li, A.; Wang, Q.H.; Chi, Y.Y.; Zhang, L.F. Experimetal study on a new type of thermal storage defrostig system for frost-free household refrigerators. Appl. Therm. Eng. 2017, 118, 256-265. [CrossRef]

28. Melo, C.; Knabben, F.T.; Pereira, P.V. A experiment study on defrost heaters applied to frost-free household refrigerators. Appl. Therm. Eng. 2013, 51, 239-245. [CrossRef]

29. Zhao, R.; Huang, D.; Zhang, Z.; Leng, Y. Effect of defrost heat leakage on freezer temperature rise during periodical defrost cycles in a frost-free refrigerator-freezer with an electric heater. Sci. Tech. Built Environ. 2017, 23, 211-217. [CrossRef]

30. Zhao, R.; Huang, D.; Peng, X.; Yang, H. Reducing cabinet temperature rise during electric heater defrosting of frost-free refrigerators by using a special fan cover to block heat infiltration. Sci. Tech. Built Environ. 2019, 25, 1505-1513. [CrossRef]

31. Zhao, R.; Huang, D.; Peng, X.; Yang, H. Distributed heaters to reduce temperature rise in freezing cabinet during defrost process and its overall energy effect for a frost-free refrigerator. Int. J. Refrig. 2019, 99, 186-193. [CrossRef]

32. Zhang, Z.; Huang, D.; Shi, L.; Chi, L. Comparison of independent and synchronous opening control strategies of two air-dampers in three-temperature frost-free refrigerator. Appl. Therm. Eng. 2018, 128, 127-133. [CrossRef]

33. Knabben, F.T.; Helmes, C.J.L.; Melo, C. In-situ study of frosting and defrosting processes in tube-fin evaporators of household refrigerating appliances. Int. J. Refrig. 2011, 34, 2031-2041. [CrossRef]

34. Moffat, R.J. Describing the uncertainties in experimental results. Exp. Therm. Fluid Sci. 1998, 1, 3-17. [CrossRef]

35. Seker, D.; Karatas, H.; Egrican, N. Frost formation on fin-and-tube heat exchangers. Part I-Modeling of frost formation on fin-and-tube heat exchangers. Int. J. Refrig. 2004, 27, 367-374. [CrossRef]

36. Barbosa, J.R.; Melo, C.; Hermes, C.J.L.; Waltrich, P.J. A study of the air-side heat transfer and pressure drop characteristics of tube-fin 'no-frost' evaporators. Appl. Energy 2009, 86, 1484-1491. [CrossRef] 